\title{
STUDENTS' ENGAGEMENT WITH PODCAST DURING LOCKDOWN - AN ANALYSIS OF INTERACTION FOOTPRINTS IN A COMPUTER SCIENCE COURSE
}

\author{
Benoit Donnet, Dominique Verpoorten, Université de Liège, Belgium
}

\section{Abstract}

This paper addresses a remote teaching activity that consists, for students, in being exposed to podcasts instead of classic face-to-face theoretical lessons. In particular, the paper discusses potential impact of podcasts on students' engagement in an introductory Computer Science course.

\section{Introduction}

During the Higher Education disruption caused by the COVID-19 (Crawford et al., 2020), podcasts were largely used as replacement or complement to the courses that could not take place on campuses anymore. Podcasting is however not new. Since its inception in 2004 (Prince, 2020), this practice has been variously described and delineated. This paper favours the following definition: "Podcasts are regularly produced digital episodes of video or audio content that are available on the Internet and can be downloaded or streamed on demand" (Hatfield, 2018). Yet, it matches the teaching method inspected here: the weekly provision of downloadable video files, released as instalments in a series, and acting as lecture content in a context of temporary online pivot (Nordmann et al., 2020). The purpose of this paper is to analyse how a group of first-year students reacted to the sudden command to study through podcasts. A better knowledge of ins and outs of such a systematic exposure to podcasts is important for the course in question (in a SoTL perspective, Felten, 2013) and, beyond, for more acute approaches of technology-enhanced learning in general (McNamara \& Drew, 2019).

\section{Method}

\section{The Course}

The course "Introduction to Programming" (abbreviated here in "CS1") is provided to first year students (Bachelor level) during the first semester of the academic year (September December) with exams in January, preceded by a 15-day study period. The CS1 course consists in theoretical lectures (10 sessions), practical sessions (exercises on paper - 10 
Donnet, B., \& Verpoorten, D.

Students' Engagement with Podcast during Lockdown - An Analysis of Interaction Footprints in a Computer Science Course

sessions), laboratory sessions (exercises in front of a computer - five sessions. Lessons and exercises sessions typically last two hours. During the Academic Year 2020-2021, 91 students were enrolled in the course, $74 \%$ of them were at their first year at the university, $12 \%$ repeated the year, and $14 \%$ reoriented from another curriculum. Among the students, $82.4 \%$ took the final January exam (organized remotely) for a pass rate of $27 \%$. Those figures are consistent with success rate at the university, for first year students, in our country (Ares, 2013-2014).

\section{Podcasts}

Podcasts are provided for each of the 8 chapters (Table 1, column 1) of the CS1 course and uploaded on the institutional intranet. An URL towards each podcast is also posted on the course LMS (Blackboard). The number of podcasts (Table 1, column 3) matches the number of sections in chapters and, according to their respective volume, covers them with varied number of slides (Table 1, column 2) and timespan (Table 1, column 4). Podcasts are released as instalments in a series (Table 1, column 5), largely on time, offering the possibility to students to watch them in advance with respect to the lessons' agenda (Table 1, column 6). Students are supposed to watch podcasts every week and internalize their content like they would do with material covered on regular face-to-face lessons (Table 1, column 6).

Table 12: Description of the course material.

\begin{tabular}{lccccc}
\hline \multirow{2}{*}{ Chapter } & \multirow{2}{*}{ \# Slides } & \multicolumn{2}{c}{$\begin{array}{c}\text { Podcast } \\
\text { \# records }\end{array}$} & total amount of time $(\mathrm{min})$. & \multicolumn{2}{c}{ Timeline $(\mathrm{mm} / \mathrm{dd})$} \\
uploaded & lessons \\
\hline 1 & 73 & 5 & 152 & $09 / 15-09 / 20$ & $09 / 23$ \\
2 & 64 & 3 & 80 & $09 / 22$ & $09 / 30$ \\
3 & 112 & 13 & 226 & $09 / 28-10 / 06$ & $10 / 07-10 / 14$ \\
4 & 67 & 6 & 90 & $10 / 06-10 / 14$ & $10 / 21$ \\
5 & 178 & 18 & 273 & $10 / 14-11 / 02$ & $10 / 28-11 / 18$ \\
6 & 110 & 14 & 205 & $11 / 17-11 / 21$ & $11 / 25$ \\
7 & 51 & 4 & 119 & $11 / 24$ & $12 / 02$ \\
8 & 42 & 7 & 84 & $12 / 01$ & $12 / 09$ \\
Total & 697 & 70 & 1,229 & & \\
\hline
\end{tabular}

The majority of our podcasts lasts between 10 and 20 minutes, which is consistent with Guo et al. (2014). This comes with multiple advantages: (a) it reduces the risk of failure during the recording, (b) the size of the podcast (in mega-bytes) is quite reasonable (52MB/podcast, on average), so that students with poor connections can still view it in (we hope) acceptable conditions, and, (c) it limits the risk students being disconnected of the lesson, due to its duration. A few longer podcasts concern use cases that must be exposed in a single shot, otherwise the whole reasoning would be broken. Most of podcasts are annotated by the teacher during the recording process (Figure 1), somehow as he would do when using a blackboard in a physical classroom. The recording process is as follows: 
Donnet, B., \& Verpoorten, D.

Students' Engagement with Podcast during Lockdown - An Analysis of Interaction Footprints in a Computer Science Course

slides are projected on the laptop, with QuickTime running in background for recording the screen and the audio. At the same time, the slides are also projected on a tablet that is used both for controlling the slides (i.e., remote control) and annotating them using a digital pencil (as a teacher would do on the board during an on-site lesson - an example of annotated slide is illustrated in Figure 1). The recording is then post-processed with QuickTime to reduce its size (i.e., resolution H.264, up to $1280 \times 720$ ). Post-processed recordings are then uploaded on the University intranet and an URL is also provided on the course virtual space.

\section{Agenda}

- Chapitre 8: Allocation Dynamique
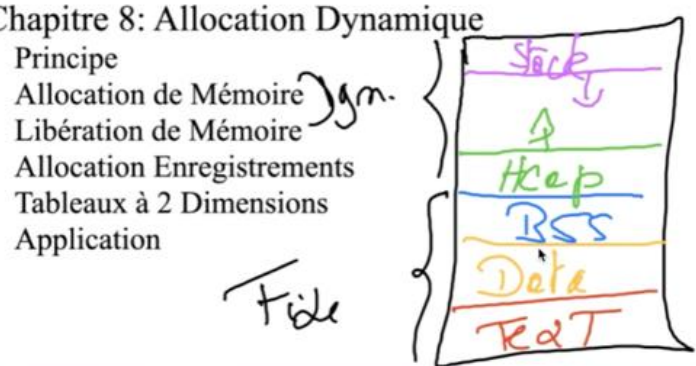

Figure 10. Example of annotated slide (Chapter 8)

\section{Data Sources}

Data was collected according to the 3 P's framework (Verpoorten et al., 2017) that recommends to consistently analyse any pedagogical innovation by gathering and meshing three types of data reflecting dimensions of students' learning experience therewith: Participation, Perception, and Performance data.

\section{Participation Data}

The University infrastructure on which podcasts are uploaded allows to track the unique number of students accessing a given podcast, as well as the number of cumulative views for each podcast. This data was collected every Friday, 06:00PM, between September $18^{\text {th }}$ and January $11^{\text {th }}$ (the day of the exam). This leads to a sample of 18 weekly series of data. Once uploaded on the University podcast platform, each podcast URL is also posted on the CS1 course blackboard. Our course blackboard comes with basic learning analytics capabilities. In particular, it records when and how often each student visits a given resource, such as a course chapter. As podcasts for a given chapter are grouped in a given repository in the blackboard, learning analytics are gathered on a per chapter basis. 
Donnet, B., \& Verpoorten, D.

Students' Engagement with Podcast during Lockdown - An Analysis of Interaction Footprints in a

Computer Science Course

\section{Perception Data}

A survey was administered to students just before the final exam. The survey was anonymous, to let the student express themselves freely.

\section{Performance Data}

Students were grouped into clusters according to the way they engage with podcasts. This is made possible thanks to Participation data collected from the CS1 course space which provides a view of students' engagement. However, it is worth noting this clustering provides a lower bound on students' engagement. Indeed, any student is always able to access to podcasts directly through the University intranet that provides a direct link towards the CS1 course podcasts. Although imperfect, this clustering provides a valuable insight into students' engagement in podcasts watching and allows the following grouping based on the engagement intensity with podcasts:

- Cluster 1 (the imperceptible) groups students who did not access to podcasts, for a given chapter, through the course blackboard.

- Cluster 2 (the discreet) groups students who did access between one and five times to podcasts, for a given chapter, through the course blackboard.

- Cluster 3 (the subscribers) groups students who did access more than six times to podcasts, for a given chapter, through the course blackboard.

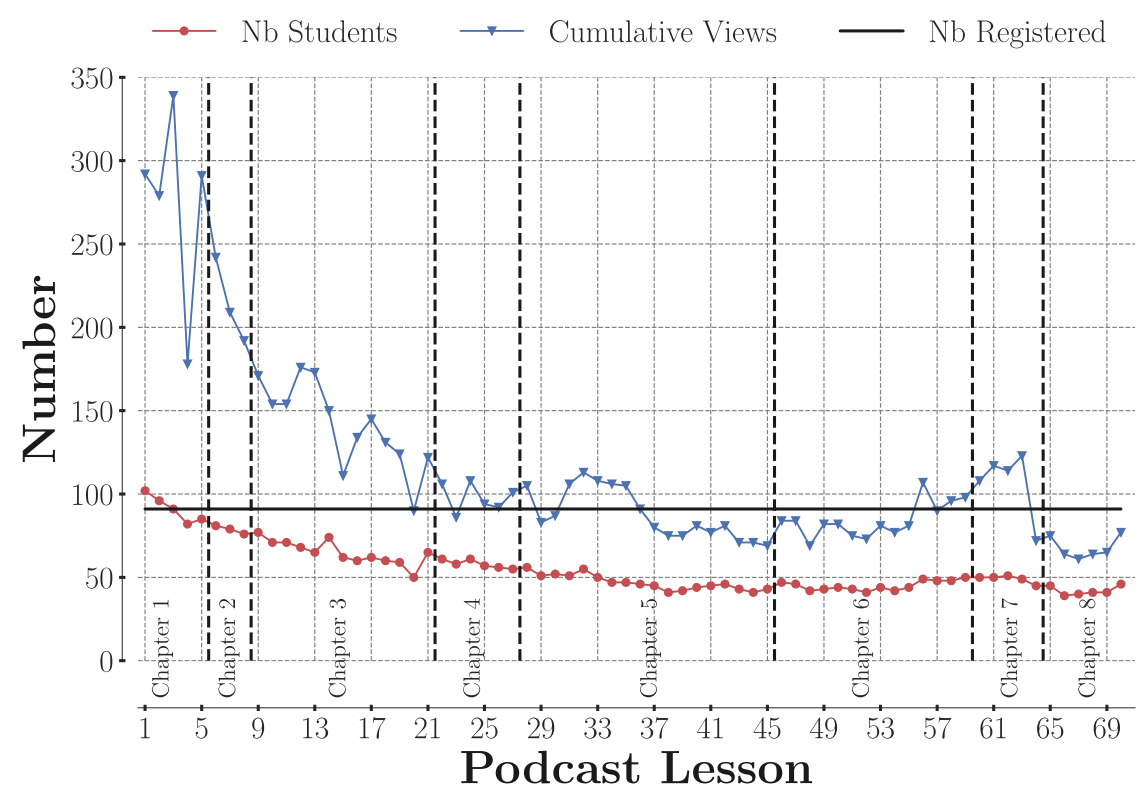

Figure 11. Total podcast viewing at the end of the course (January, $11^{\text {th }}$ ) 
Donnet, B., \& Verpoorten, D.

\section{Students' Engagement with Podcast during Lockdown - An Analysis of Interaction Footprints in a Computer Science Course}

\section{Results}

\section{Participation}

Overall, the podcasts were seen 8,147 times (Figure 2, blue line), that is an average view by enrolled students of 89. Most of the podcasts are seen twice (Figure 2, see the gap between the blue curve - cumulative views - and the red curve - unique number of students). Also, the students' engagement tends to decrease over time: unique users fade as well as the number of views. Finally, on Figure 2, the horizontal line provides the number of students registered to the course (91). It may seem odd that, for the first podcasts, the number of unique students is slightly higher than the number of registered students. The reason for this is that a few students have left the curriculum early in the semester because, e.g., they want to reorient themselves. As those students, finally, do not really account during the remainder of the semester, they were removed them from the sample.

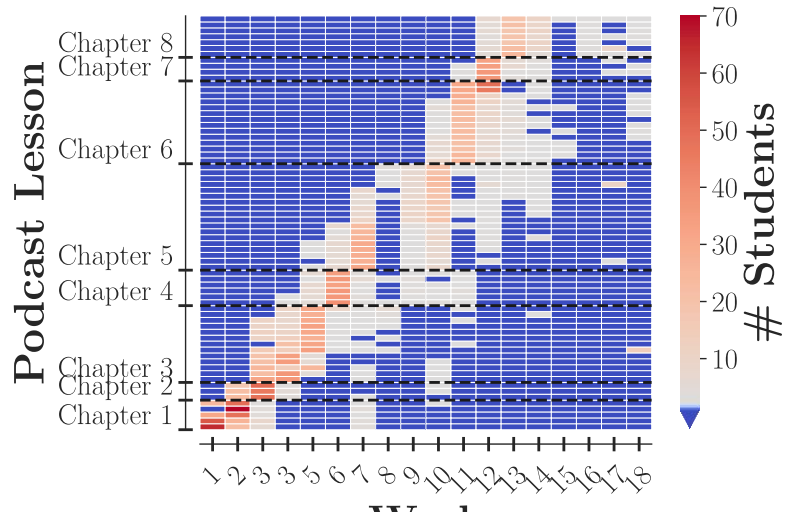

Week

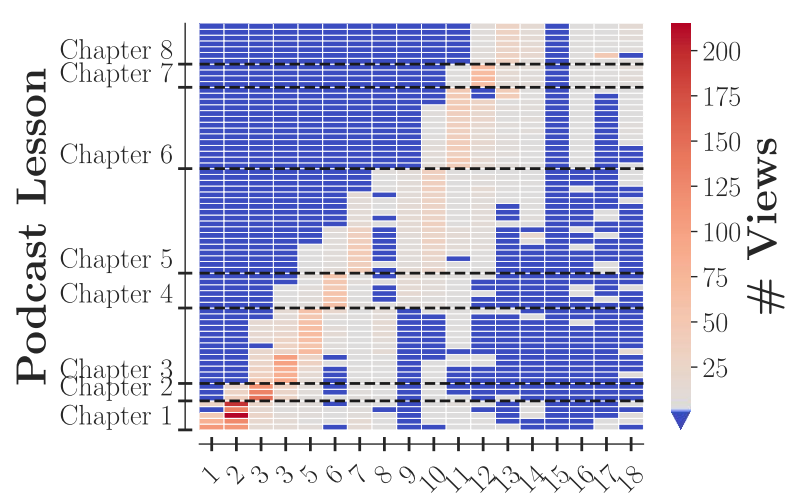

Week

Figure 12. Podcast access over time per student (left) and per viewing (right)

Fig. 3 shows how students interact with the podcasts throughout the semester. The X-Axis gives the time (as week numbers), while the Y-Axis provides the different podcasts, organized by chapter. The colour bar provides either the unique number of students accessing a podcast (Figure 3, left) or the number views of a podcast over the course duration (Figure 3, right). Figure 3 (left) shows that students, typically, follows the podcast publication cycle to access them, except for Week 7 (which corresponds to a Mid-Term exam), where one observes a slight increase. The situation is a little bit different for the number of viewings (Figure 3, right) as chapters seem to be viewed over a (slightly) larger period of time. This is particularly true with Chapter 1 for which podcasts are accessed nearly every week during the semester. 
Donnet, B., \& Verpoorten, D.

Students' Engagement with Podcast during Lockdown - An Analysis of Interaction Footprints in a

Computer Science Course

\section{Perception}

The questionnaire brought about 79 answers, that is the majority of the students who took the final exam (90\%). Main observations are: (a) 77\% of respondents estimates having watched more than $75 \%$ of the available podcasts (44\% having watched all of them - this is consistent with the red curve on Figure 2). (b) $80 \%$ of students acknowledges the usefulness of podcast annotations. Finally, the majority of respondents (55\%) expresses that the ideal podcast duration is between 10 and 20 minutes.

\section{Performance}

The cluster distribution (Figure 3, left) provides a view of students' engagement and tries to trace its effect on performance. Indeed, as shown in Table 2, belonging to Cluster 2 and 3 for a given chapter means that students have covered most of the chapter podcasts.

Table 2: $\quad$ Chapter coverage per cluster. The percentage is computed based on the number of records per chapter (see Table 1).

\begin{tabular}{ccccccccc}
\hline & \multicolumn{10}{c}{ Chapter } \\
& 1 & 2 & 3 & 4 & 5 & 6 & 7 & 8 \\
\hline Cluster 1 & $0 \%$ & $0 \%$ & $0 \%$ & $0 \%$ & $0 \%$ & $0 \%$ & $0 \%$ & $0 \%$ \\
Cluster 2 & $\leq 100 \%$ & $\leq 100 \%$ & $\leq 38 \%$ & $\leq 83 \%$ & $\leq 27 \%$ & $\leq 35 \%$ & $\leq 100 \%$ & $\leq 71 \%$ \\
Cluster 3 & $100 \%$ & $100 \%$ & $>38 \%$ & $>83 \%$ & $>27 \%$ & $>35 \%$ & $100 \%$ & $>71 \%$ \\
\hline
\end{tabular}

Figure 4 (right) deepens the analysis by looking at clusters on a per student basis. The $\mathrm{X}$-Axis provides the various course chapters, while the Y-Axis provides students identifier (anonymized). These refined learning analytics show that a portion of students are stable over time, i.e., they never leave their cluster, they stay in Cluster 1 or Cluster 2 throughout the semester. A few students exhibit a "slow start" behaviour, beginning in Cluster 1 and moving to Cluster 2 (sometimes even Cluster 3) as the semester goes by. On the contrary, others suggest a drop-out trajectory, starting the semester in Cluster 2 and slightly plummeting to Cluster 1 . 

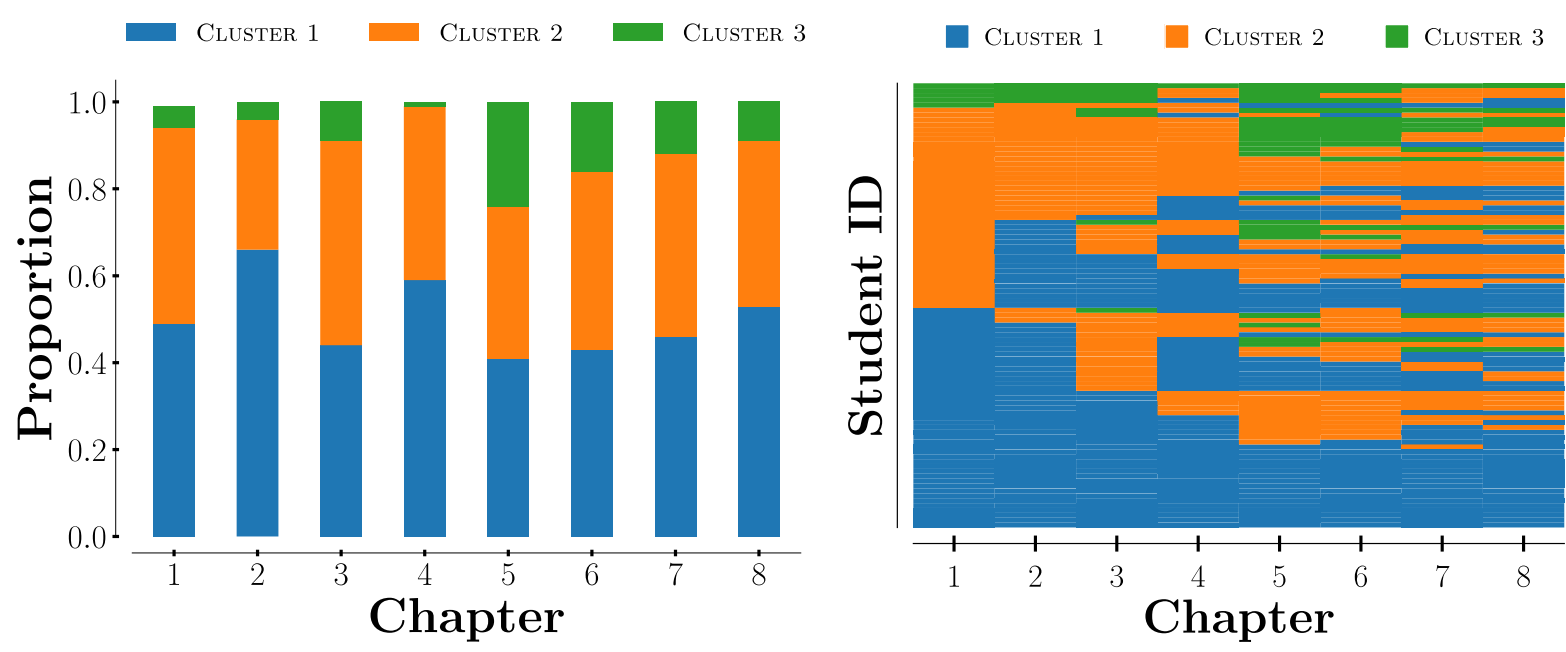

Figure 4. Podcast clustering distribution (overall distribution - left - and per student - right)

Table 3: $\quad$ Probability of succeeding/failing at the exam according to the average cluster membership over the semester $(N=91)$.

\begin{tabular}{lcc}
\hline & Raw & Percentage \\
\hline Pr[Pass | Cluster 1] & 6 & $6.6 \%$ \\
Pr[Fail | Cluster 1] & 30 & $33 \%$ \\
Pr[Drop Out | Cluster 1] & 4 & $4.4 \%$ \\
Pr[Pass | Cluster 2] & 13 & $14.3 \%$ \\
Pr[Fail | Cluster 2] & 32 & $35.2 \%$ \\
Pr[Drop Out | Cluster 2] & 0 & $0 \%$ \\
Pr[Pass | Cluster 3] & 1 & $1.1 \%$ \\
Pr[Fail | Cluster 3] & 5 & $5.5 \%$ \\
$\operatorname{Pr}[$ Drop Out | Cluster 3] & 0 & $0 \%$ \\
\hline
\end{tabular}

\section{Discussion}

The main result of this study is counter-intuitive (but not totally isolated, Williams et al., 2016; Lindsay \& Evans, 2021): watching podcasts does not make a difference. Statistical tests confirm what is observable from mere percentages in Table 3: a) not watching podcasts is no absolute reason for failure (Table 3, cluster 1, line 1). As the course evaluation is only practical (i.e., exercises resolution), reading the written material and doing weekly exercises may be enough for some students, b) the percentage of failure is roughly the same among the "imperceptible" and the "discreet" clusters (Table 3, line 2 and line 5), the "subscribers" cluster does not bring home more success (Table 3, line 7 and line 8). This has important consequences for CS1 regulation: is it worth lecturing in podcasts (or even in face-to-face)? Contribution to the field is also noticeable: the lack of relationship between podcast watching and success in the course should exercise caution, when using learning analytics, one is tempted to establish quick connections between interaction footprints somehow reflecting engagement and performance (Wold, 2018). The study also brings about a minor input: while it is often argued by proponents of 
Donnet, B., \& Verpoorten, D.

Students' Engagement with Podcast during Lockdown - An Analysis of Interaction Footprints in a Computer Science Course

asynchronous content (screencasts, live lecture captures, Web lectures) that the permanent availability of such resources allows students to study them at their own pace and as much as they need (Nielsen et al., 2018), the results here rather show even use of the podcasts (Figure 3). Students look at them once and do not seem to take advantage of the fact they can watch them again for better fixing the lesson content. Of course, both conclusions can be marred by the major limitation of the study: the impossibility for the researchers to guarantee that, at this early stage of learning analytics exploitation (Hausman et al., 2020), no podcast viewing has escaped their compilation. Although negative, this experienced difficulty is a contribution of its own to the field.

\section{References}

Académie de Recherche et d'Enseignement Supérieur (ARES) (2013 - 2014). Indicateurs de l'Enseignement Supérieur. Retrieved from https://www.aresac.be/fr/statistiques/indicateurs

Beaubouef, T., \& Mason, J. (2005). Why the High Attrition Rate for Computer Science Students: Some Thoughts and Observations. ACM SIGCSE Bulletin, 37(2), 103-106. doi:10.37074/jalt.2020.3.1.7

Crawford, J., Butler-Henderson, K., Rudolph, J., Malkawi, B., Glowatz, M. Burton, R., \& et al. (2020). COVID-19: 20 Countries' Higher Education Intra-Period Digital Pedagogy Responses. Journal of Applied Learning \& Teaching, 3(1), 9-28. doi: $10.1145 / 1083431.1083474$

Felten, P. (2013). Principles of Good Practice in SoTL. Teaching and Learning Inquiry, 1(1), 121-125. doi:10.2979/teachlearninqu.1.1.121

Guo, P. J., Kim, J., \& Rubin, R. (2014). How Video Production Affects Student Engagement: An Empirical Study of MOOC Videos.Proc. ACM Learning @ Scale Conference(L@S, Melbourne, 41-50.doi:10.1145/2556325.2566239

Hatfield, E. F. (2018). Narrative Learning Using Podcasts Interpersonal. Communication Teacher, 32(4), 236-242. doi: 10.1080/17404622.2017.1372790

Hausman, M., Verpoorten, D., Defaweux, V., \& Detroz, P. (2020). Learning Analytics: A Lever for Professional Development of Teachers? In W. Nuninger \& J.-M. Châtelet (Eds.), Handbook of Research on Operational Quality Assurance in Higher Education for Life-Long Learning (pp. 308-335). IGI Global. doi:10.4018/978-1-7998-1238-8.ch013

Howard, E., Meehan, M., \& Parnell, A. (2018). Live Lectures or Online Videos: Students' Resource Choices in a First-year university mathematics module. International Journal of Mathematical Education in Science and Technology, 49(4), 530-553. doi:10.1080/0020739X.2017.1387943 
Donnet, B., \& Verpoorten, D.

Students' Engagement with Podcast during Lockdown - An Analysis of Interaction Footprints in a

Computer Science Course

Lindsay, E., \& Evans, T. (2021). The Use of Lecture Capture in University Mathematics Education: a Systematic Review of the Research Literature. Mathematics Education Research Journal, 1-21. doi:10.1007/s13394-021-00369-8

McNamara, S., \& Drew, C. (2019). Concept Analysis of the Theories Used to Develop Educational Podcasts. Educational Media International, 56(4), 300-312. doi:10.1080/09523987.1681107

Nielsen, S. N., Andersen, R. H., \& Dau, S. (2018). Podcast as a Learning Media in Higher Education. Proc. $17^{\text {th }}$ European Conference on e-Learning (ECEL), Athens, 424-430.

Nordmann, E., Horlin, C., Hutchison, J., Murray, J.-A., Robson, L., Seery, M. K., \& MacKay, J. R. D. (2020). Ten Simple Rules for Supporting a Temporary Online Pivot in Higher Education. PLOS Computational Biology, 16(10), e1008242. doi:10.1371/journal.pcbi.1008242

Prince, B. (2020). Podcasts: The Potential and Possibilities. Teaching Sociology, 48(4), 269-271. doi:10.1177/0092055X20959837

Verpoorten, D., Parlascino, E., André, M., Schillings, P., Devyver, J., Borsu, O., van de Poel, J.-F., \& Jerome, F. (2017). Blended Learning - Pedagogical Success Factors and Development Methodology. (Tech. Rep.) Université de Liège, Beligum: IFRES.

Watson, C., \& Li, F. W. (2014). Failure Rates in Introductory Programming Revisited. Proc. Conference on Innovation \& Technology in Computer Science Education (ITiCSE), Uppsala, 39-444. doi:10.1145/2591708.2591749

Williams, A. E., Aguilar-Roca, N. M., \& O’Dowd, D. K. (2016). Lecture Capture Podcasts: Differential Student Use and Performance in a Large Introductory Course. Educational Technology Research and Development, 64(1), 1-12. doi:10.1007/s11423015-9406-5

Wold, M. (2018). Students' Usage Patterns of Video Recorded Lectures in an Undergraduate Mathematics Course. Paper presented at the INDRUM 2018 Conference, Kristiansand, Norway. 